Para enlazar con este artículo / To link to this article:

https://doi.org/10.6035/MonTI.2020.12.08

Para citar este artículo / To cite this article:

Díaz Díaz, Teresa. (2020) "La traducción de conceptos y obras artísticas a través del tacto: un sentido olvidado en la teoría y práctica de la traducción." En: Richart-Marset, Mabel \& Francesca Calamita (eds.) 2020. Traducción y Accesibilidad en los medios de comunicación: de la teoría a la práctica / Translation and Media Accessibility: from Theory to Practice. MonTI 12, pp. 242-261.

\title{
LA TRADUCCIÓN DE CONCEPTOS Y OBRAS ARTÍSTICAS A TRAVÉS DEL TACTO: UN SENTIDO OLVIDADO EN LA TEORÍA Y PRÁCTICA DE LA TRADUCCIÓN
}

\author{
TERESA DíAZ DíAZ \\ t.diaz.2017@alumnos.urjc.es \\ Escuela Internacional de Doctorado \\ Universidad Rey Juan Carlos
}

\section{Resumen}

En el mundo de la investigación en traducción, tanto en teoría de la traducción como en traductografía, no hay apenas mención alguna al sentido del tacto para traducir conceptos en el ámbito de las personas con discapacidad visual. Todo se centra en la audiodescripción para ciegos, sin percatarse que la persona con discapacidad visual no solamente utiliza el oído para captar el mundo circundante y aprender nuevas disciplinas, sino también el olfato, el gusto y el tacto, sentido fundamental entre los ciegos. La falta de textos al respecto consideramos que se debe a que todos los esfuerzos en hacer aprender a las personas con discapacidad visual han estado enfocados a lo largo de la historia en intentar entenderse a través del lenguaje oral, tanto para los que tenían un pequeño resto visual, como para los que no veían nada.

Palabras Clave: Traductología; Interpretación; Textos; Ciegos; Tacto.

\section{Abstract}

The translation of artistic concepts and works through touch: a forgotten sense in the theory and practice of translation

In the world of translation research, both in translation theory and in translated texts, there is hardly any mention of the sense of touch to translate in the field of the disabled 
recipient. Everything is focused on audiodescription for the blind, without realizing that the visually impaired not only use the ear to capture the surrounding world and learn new disciplines, but also smell, taste and touch, which is a fundamental sense for the blind. The lack of texts in this field may be due to the fact that all efforts to make visually-impaired people learn have been focused on trying to understand each other through oral language, both for those who had a low vision and for those totally blind.

Keywords: Translatology; Interpreting; Texts; Blind; Touch.

\section{Breves apuntes sobre la evolución histórica de la discapacidad}

Para vislumbrar la evolución histórica de la discapacidad y comprender el modo de traducir ideas y conceptos, desde temas complejos hasta los aspectos más cotidianos, tenemos que bucear en el pasado.

Históricamente, en las sociedades antiguas de Grecia y Roma se tiene constancia, a través de Aristóteles (1971: 145), que estaba bien visto dar muerte a los niños que nacían deformes, debido en parte al culto por mantener la perfección corporal y también porque en el caso de llegar a crecer, no encontrasen su espacio en la sociedad.

La concepción de la discapacidad en los siglos XV y XVI comenzó a cambiar tímidamente hasta ir aceptando poco a poco a las personas con discapacidad en su comunidad. El modelo medieval, caracterizado por la justificación religiosa de la discapacidad como castigo al pecado y la consideración de que estas personas eran una carga, y por tanto prescindibles, lo que Palacios Rizzo (2008: 25) denomina "modelo de prescindencia"), dio paso a la aceptación de las personas con discapacidad. A pesar de ello, sus condiciones de integración en las sociedades preindustriales estaban limitadas, debido a la carencia de un sistema de formación y el consiguiente acceso a puestos de trabajo con los que se pudiesen incorporar a los sistemas de producción.

Antes de la llegada de los españoles al continente americano, en 1492, las personas con discapacidad eran abandonadas y su destino a corto plazo era la muerte. En algunas sociedades, posteriormente se produce una merma de la población indígena, debido a los trabajos forzados y las epidemias, lo que fomentaba la compra y venta de esclavos, transacción de seres humanos en la que los enfermos, ancianos y aquellos que tenían algún tipo de discapacidad eran mano de obra más barata. Posteriormente, con la reforma 
protestante, entre finales del siglo XV y comienzos del siglo XVI, se pensaba que las personas con discapacidad estaban "poseídas por el demonio", y en algunas ciudades alemanas se las paseaba en las llamadas "jaulas de idiotas". Asimismo, en las colonias inglesas de Norteamérica apodaban "tonto del pueblo" a las personas con discapacidad mental. Lo normal era aislarlos de la sociedad, recluyéndolos en asilos o manicomios.

A partir del siglo XVI, en algunos estados europeos comenzaron a interesarse por la idea de que debía existir una responsabilidad social hacia las personas con discapacidad, calando sobre todo en la educación de personas sordas en Gran Bretaña, Holanda, algunos estados alemanes y la península itálica. Evidencia de ello, y de su preocupación por las personas con discapacidad, nos la ofrece el humanista español Juan Luis Vives (1492-1540) en su libro titulado De subventione pauperum. Sive de humanis necessitatibus libri II (1526), donde propone un plan de actuación contra la pobreza, al tratar el problema de la mendicidad y buscar soluciones en las instituciones públicas, que son, a su juicio, quienes deben socorrer a los pobres y hacer trabajar a todo el mundo; para ello propone una organización fundada en la beneficencia y una reforma del sistema sanitario y de asilo.

En Francia, en el siglo XVIII se inicia una enseñanza basada en la lengua de signos, proyecto que ya en 1620 Juan de Pablo Bonet sacaba a la luz con la publicación de un libro titulado Reducción de las letras y Arte para enseñar a hablar a los Mudos, considerado el primer tratado moderno de Fonética y Logopedia pensada para personas sordas o sordociegas.

\section{La invención del sistema de lectura y escritura Braille}

No cabe duda de que el proceso está en marcha. Durante el siglo XIX, los avances anteriores van a dar su fruto en el campo de la educación. A nivel general en las personas con discapacidad y a nivel particular en en el campo de la ceguera. Su precursor, el lingüista francés Valentin Haüy (1745-1822) funda la Institución Real para los jóvenes ciegos en 1784, Fundación creada para la educación, para la instrucción en algún tipo de trabajo manual y para promover el empleo para las personas ciegas.

Al mismo tiempo, diseña el primer sistema de lectura y escritura accesible a los ciegos, para ser descifrado con el tacto, constituido sobre la puesta en 
relieve de las letras romanas, es decir los caracteres visuales que utilizaban las personas videntes. Se trataba de un proceso de impresión de tipos de gran tamaño, en relieve y con tinta negra, sobre cartulina húmeda; aquellas letras y cifras podían ser leídas con los dedos. Con textos así preparados numerosos ciegos aprendieron a leer, conocieron las normas básicas de la ortografía, pudieron escribir y llegaron a manejarse con las cuatro operaciones aritméticas fundamentales.

Haüy es conocido por ser autor de un ensayo sobre la educación de los ciegos, escrito en 1786, por su competencia en obtener procesos sistematizados, hasta ese momento reservados para los 'privilegiados raros', y por conseguir en bloque que todos los ciegos pudieran capacitarse, en el amplio sentido de la palabra.

Le sucede el intuitivo oficial de ejército francés Charles Barbier (17671841). Barbier, que ejerció de capitán de artillería durante la Revolución francesa, se interesa por la escritura rápida y secreta, obsesionado por los lenguajes codificados, e ideó en 1821 un sistema conocido como Sonógrafo de Barbier. Básicamente se trataba de un sistema de 12 puntos que permitía traducir las palabras en sonidos y servía para transmitir órdenes de avanzadilla en el frente, sin tener necesidad de delatar la posición durante las noches; es decir, que se hacía a oscuras. Este alfabeto consistía en una estructura fonética y grafía de puntos a la que denominó sonografía, realizado con un lapicero tipo buril para poder ser leídos los puntos con las yemas de los dedos. Así pues, para su creación se utiliza un elemento común al que utilizaban los escultores, ofreciéndonos así una primera idea de la relación entre ceguera y aprendizaje del arte a través del tacto.

Presentó su proyecto a la Real Academia de las Ciencias de Francia, la cual animó a Charles Barbier a que lo mostrase en el Institut National des Jeunes Aveugles (Real Institución para Jóvenes Ciegos). A partir de entonces, esta institución adoptó el sistema Barbier en sustitución del que se venía utilizando. Un paso adelante y un significativo progreso sobre estos dos métodos y que, además, revolucionaría el sistema de Barbier formado por ocho puntos en relieve, lo daría un alumno de Valentin Haüy llamado Louis Braille, ciego desde los cuatro años, al que se le ocurrió simplificar el número de puntos y reducirlo a seis en una cuadrícula a $3 \times 3$, al darse cuenta de que ese número era el que entraba en la yema de un dedo y le resultaba más cómodo y rápido 
de leer. De este modo dio con el sistema de lecto-escritura que lleva su nombre y que con el paso del tiempo se convertiría en un sistema universal del que podrían disfrutar todos los ciegos del mundo a partir de ese momento.

\section{El aprendizaje a través del tacto}

Pero lo mismo que una persona que ve aprende a través de la vista, como decía Oskar Kokoschka cuando creó Die Schule des Sehens (Escuela de Ver) en Salzburgo en 1953, como cursos de verano en la disciplina de las Bellas Artes para futuros pintores y escultores, las personas con discapacidad visual pueden aprender a conocer e interpretar el arte a través del tacto. Kokoschka, en su autobiografía, afirmaba que el mundo se puede captar desde la más tierna infancia bien a través de la vista y de la concepción espacial, o bien a través del oído, mejorando en este caso la capacidad lingüística desde niño (Martino Alba 2016: 244-246). Sin embargo, a pesar de haberse dedicado también a la escultura, no hace referencia en su texto autobiográfico al aprendizaje a través del sentido del tacto. Pero no solamente la escultura como disciplina artística en que la forma en tres dimensiones facilita que sea palpada, sino que también se puede disfrutar de otras bellas artes y, concretamente, aunque parezca imposible, de la arquitectura. Incluso se puede aprender arquitectura a través del tacto, como demuestra el uso de maquetas arquitectónicas de monumentos Patrimonio de la Humanidad que se hallan en el Museo Tiflológico o museo para ciegos (Institución Cultural de la ONCE con sede en Madrid). Pues bien, como veremos más adelante, desde la perspectiva de la teoría de la traducción y de diversas disciplinas relacionadas con la traducción, como puede ser la terminología, no se contempla la posibilidad de aprender nuevos términos específicos a partir del tacto.

De las tres ramas de las Bellas Artes consideradas como Artes mayores -a saber: arquitectura, escultura y pintura- vemos que sí hay instituciones, como en el caso de la arquitectura el arriba mencionado Museo Tiflológico, que se ocupan de promover el aprendizaje del arte a través del tacto y, consecuentemente, la transmisión de ideas y conceptos a través de este importante sentido. Así, por ejemplo, el aprendizaje de la escultura a través del tacto en el Museo Omero de Ancona (Italia) o el aprendizaje de la pintura a través del tacto con la introducción de las nuevas tecnologías y la impresión y reproducción en 
3D de relevantes obras pictóricas realizadas por el Museo Anteros de Bolonia (Italia). Aunque los ciegos no puedan ver el color, pueden ver las formas; la diferente textura y rugosidad de partes de esas formas los lleva a comprender la obra. Estos y otros museos se van adhiriendo a proporcionar accesibilidad a las personas con discapacidad, considerándose una prioridad absoluta, idea que va calando y se irá incorporando poco apoco en todos, con el fin de cumplir la normativa para ser inclusivos, hasta formar un punto de encuentro en grupos culturales. Al respecto, la legislación española sobre museos establece la obligación de hacer adaptaciones, pero no define los términos, ni indica cómo, ni qué cantidad de la colección debe estar accesible.

Si establecemos un paralelismo entre el efecto que produce en una cultura receptora el que grandes obras de la literatura se traduzcan a otra lengua -efecto que, indudablemente, supone un enriquecimiento de ese otro polisistema cultural que recibe a un autor extranjero y la consecución de un paso más en el derecho a la cultura de todos los ciudadanos- y el efecto que produce en un colectivo de ciegos la recepción de ideas y conceptos artísticos que le estaban vetados, entenderemos quizá mejor la pertinencia de incluir el tacto entre los sentidos hasta ahora olvidados en la teoría de la traducción, tradicionalmente focalizada sobre textos, entendidos estos prácticamente en su totalidad como textos escritos, si bien con alguna incursión teórica relevante en los últimos años en los textos orales y en la transmisión de culturas ágrafas a través de la fijación textual (Vega Cernuda 2013: 22-42).

Desde el punto de vista de la teoría de la traducción, un primer acercamiento nos llevaría, en buena lógica, a relacionar el tema que tratamos con los presupuestos de la traducción intersemiótica, pues en esencia pasamos de un sistema de signos a otro: de un sistema táctil a otro que recopila memorísticamente a través del tacto y también del oído, debido a las explicaciones teóricas que deben acompañar en ese proceso de enseñanza-aprendizaje, y que permitirá la reproducción de ese aprendizaje a través de la palabra. Sin embargo, vayamos al primer peldaño, considerado este como la definición de traducción entre los traductólogos. A partir de esa primera definición, trataremos de hacer un recorrido por los diferentes textos teóricos, con el fin de indagar si se ha tratado en algún momento de acercar la discapacidad visual al sentido del tacto como medio para transmitir ideas y conceptos directamente relacionados con las artes plásticas. 


\section{La teoría de la traducción y el sentido del tacto como medio de transmisión de conocimientos y de traducción de la realidad}

Antes de tomar como punto de partida los rasgos definitorios de la traducción que Amparo Hurtado recoge en su conocido manual de consulta, destaca la necesidad de desarrollar una habilidad de transferencia, que Hurtado (2001: 30) resume en la posesión de capacidad de comprensión y producción de textos (en la bibliografía sobre teoría de la traducción el término texto se refiere prácticamente en exclusiva al texto escrito) y en una predisposición a aceptar el cambio de un código lingüístico a otro sin interferencias; pues bien, tanto ese código de partida como el de llegada puede que no sean ninguno de los dos códigos lingüísticos y, también en este caso, según nuestra modesta opinión, podríamos hablar de traducción o, si se quiere, de interpretación del texto original. La traducción es, fundamentalmente, un acto de comunicación y llámese de una u otra manera, en el caso de los ciegos (y de los tres museos mencionados al inicio), nos parece meridianamente claro que interpretan el espacio arquitectónico y el tiempo histórico a través del tacto en el Museo Tiflológico, el volumen y el movimiento escultóricos en el Museo Omero y el color y la composición pictóricos a través de las diferentes texturas de los materiales utilizados en la reproducción en 3D en el Museo Anteros.

Vayamos, pues, a esos rasgos definitorios que menciona Hurtado (2001: 31), quien, entre los principios básicos de la traducción, menciona los siguientes: la primacía de la comunicación y la adecuación a la lengua de llegada; la actualización textual: el sentido; la intervención del contexto; los aspectos culturales y el destinatario de la traducción; la importancia de la adscripción textual y de la finalidad de la traducción y, por último, la traducción como un proceso mental. Cada uno de esos rasgos definitorios que en el texto de Hurtado se refieren a textos escritos y, en algunos casos, también a textos visuales, es indudable que en ninguno de ellos se hace referencia a textos táctiles.

En el primero de los rasgos, es decir, la primacía de la comunicación y la adecuación a la lengua de llegada, se hace alusión a las fórmulas que cada lengua emplea para buscar los equivalentes, lo que para Eugene Nida respondía al concepto de equivalencia dinámica y que es fundamental para que la traducción de un texto, sea sobre el soporte que sea -dicho sea de 
paso-, cumpla su función. Por lo que respecta al segundo de los rasgos -a saber, la actualización textual: el sentido-, Hurtado afirma que, para no caer en la intraducibilidad, no debemos pensar únicamente en los elementos lingüísticos sino también en la simbiosis entre texto e imagen, conjunto que en nuestro objeto de estudio puede tratarse de imagen mental cuya forma se percibe por el tacto. Si ahora nos adentramos en el tercero de los rasgos, el que hace alusión a la posible intervención del contexto en el proceso traductor, pensemos por un momento en que la persona con discapacidad visual podría interpretar una forma cónica no sólo como una figura geométrica y describirla simplemente como un cono, sino que podría tener otras connotaciones y consiguientes interpretaciones posibles: volcán, tipi, pecho, embudo, etc. En lo que se refiere a los aspectos culturales y el destinatario de la traducción como cuarto de los rasgos mencionados por Hurtado, es indudable que el ciego interpreta el texto táctil según su bagaje cultural y, cuanto mayor y más profundo sea, mejor transmitirá al oyente ciego, como miembro de un público meta, lo que lee con el tacto y los ojos de la mente, concepto al que volveremos más adelante. Hurtado habla también de la importancia de la adscripción textual y de la finalidad de la traducción como paso previo para una correcta interpretación del texto original, así como para una buena calidad del producto final. Esta idea, trasladada a nuestro objeto de investigación, se referiría a la distinción por parte del traductor e intérprete ciego de las formas arquitectónicas, escultóricas y pictóricas en relieve y al conocimiento tanto del estilo artístico como del periodo histórico en que cada una de las obras a interpretar se enmarca.

Por último, entre los rasgos definitorios de la traducción, Hurtado habla de la traducción como proceso mental, como un proceso cognitivo necesario para que la traducción se haga realidad. Pues bien, no cabe duda de que, en el traductor e intérprete invidente, el proceso cognitivo exige un esfuerzo mayor, puesto que aquí no cabe la posibilidad de acudir a textos escritos como textos paralelos, a no ser que sean audiolibros, o a otras fuentes, táctiles o acústicas, que ayuden a interpretar el objeto artístico que palpa para leerlo, aprender sobre su contenido a partir de su forma, e interpretarlo.

Si consideramos que un texto escrito cuyo contenido verse sobre algunas de las tres artes mayores -a saber: arquitectura, escultura y pintura- es un texto histórico-artístico, y nos fijamos en la definición que del texto artístico 
ofrece Sáez Hermosilla (2002), nada impide considerar las maquetas de obras arquitectónicas, las esculturas o la reproducción de obras pictóricas en 3D como textos artísticos escritos en un código no lingüístico, pero que pueden, en buena lógica, ser leídos por medio del tacto e interpretarse culturalmente:

Los textos artísticos están determinados por la función expresiva y la poética, son altamente culturales y específicamente subjetivos, son marcadamente simbólicos y tienen un gran poder de evocación y de connotación [...] admiten interpretaciones múltiples, es decir, que son plurívocos o polisémicos o ambiguos, trascienden por su carácter de universalidad el tiempo y la circunstancia en que fueron concebidos y escritos (Sáez Hermosilla 2002: 51).

Acudiendo a teóricos de mayor repercusión internacional y a la historia de la teoría de la traducción, esta forma de pasar de un texto expresado en un código no lingüístico, en el que el relieve, las texturas y las formas dan sentido al texto de partida para ser leído e interpretado en otro código, convirtiéndose en un texto de llegada que el ciego ve con los ojos de la percepción táctil y de la mente, nos lleva a traer a colación la teoría francesa de las 'bellas infieles' y la teoría de la 'manipulación' en los textos literarios, teorías que pueden ser aplicadas asimismo a un nuevo enfoque que tenga en cuenta el tacto como sentido fundamental para la comunicación en torno a obras histórico-artísticas. No cabe duda de que cada persona con discapacidad visual interpretará el texto según su bagaje cultural y su formación previa en teoría estética y en historia y teoría de las artes plásticas, pero también en función de su dominio de un buen estilo literario, oratorio y retórico, ya que esto es necesario para que el invidente explique a otros congéneres lo que está leyendo con el tacto. En este sentido, no podemos obviar la función de los audiolibros como fundamental para la formación literaria de los ciegos. Esos conocimientos enciclopédicos, que los teóricos de la traducción aducen como necesarios para que un texto cumpla con los requisitos de calidad y función en la cultura de llegada, son perfectamente aplicables al colectivo de personas con discapacidad visual.

En ese proceso de interpretación y de verbalización de lo que palpa y cómo lo entiende, no hay nadie más visible que el invidente. En este sentido, el colectivo con discapacidad visual como intérpretes de la realidad artística que manipulan se contrapone a la teoría venutiana de la invisibilidad del traductor. Lo mismo podríamos afirmar que sucede con diferentes traductores literarios ante un texto, es decir, que lo interpretarán y traducirán según sean 
sus conocimientos sobre el autor, su contexto creativo, su obra y, cómo no, sobre la historia de la literatura en la cultura de partida y su dominio de la expresión literaria en la lengua de llegada. Aun dominando el estilo del autor en lengua original, es indudable que dejan su impronta en el texto traducido $y$, aunque no sea este el momento y el lugar para adentrarse en esta afirmación, en incontables ocasiones se reconoce de manera palpable el estilo del traductor literario, lo que, según nuestro modesto entender, es una impronta que dignifica al profesional de la traducción literaria.

El derecho al acceso a la cultura abarca a un colectivo, dentro del ámbito de las diferentes discapacidades, que no se ha tenido en cuenta desde la teoría de la traducción. Ésta, en realidad, se ha limitado a indagar en el sentido del oído, pareciendo que toda imagen debe ser entendida, comprendida y aprendida por parte de las personas con discapacidad visual a través del oído, es decir con la descripción directa de la pieza o la audiodescripción en una audioguía, a modo de trasladar la información de la obra de arte a palabras, sin tener en cuenta que el ciego o deficiente visual percibe mucho más a través de los impulsos que recibe por medio de las yemas de los dedos.

El caso de la descripción -y, en el ciego cognitivo, el relato- se va a ir transformando en su mente, para hacerse la idea mental, idea que se completará cuando pueda hacer la exploración táctil. Es un esquema parecido a la fijación de imágenes nuestras, como en el caso de la fotografía, pero para el que nunca ha visto, esa traducción realizada por su interlocutor será clave para fijar su pensamiento, sobre todo en los casos que no son objetos exentos, como por ejemplo una taza, o un objeto cotidiano en el que puede percibir toda su forma y volumen, como sucede con las esculturas, que al poder abarcarlas y tocarlas, son el soporte que más les gusta dentro de las artes plásticas. En cambio, la traducción de obras de arte, acompañada de la descripción verbal, hará que su mente vaya formando ese cuadro en su memoria, totalmente imaginario.

\section{Fragmentos de interpretación de obras artísticas por parte de artistas con discapacidad visual}

Muchos piensan que el mayor favor que se puede hacer a las personas ciegas es aportarles al máximo los medios para que puedan ser como nosotros; pienso que es un error, porque existen múltiples y diferentes formas de 
percibir. ¿ No es curioso que en un gran número de antiguas civilizaciones el ciego haya sido considerado más vidente que los videntes, hasta tal punto que Edipo se saltara los ojos para ver cuando el anciano ciego Tiresias veía lo que Edipo no podía ver porque sus ojos estaban abiertos? Por ello, para poder entender lo que sucede con la ceguera y su relación con el arte, tenemos que tener primero bien claros dos conceptos fundamentales: percepción y ceguera (Luz Arqué 2005: 17-24).

¿Se puede tener discapacidad visual y crear arte? Sí, se puede. De hecho las obras plásticas que realizan, algunas de ellas ciertamente de alto valor artístico, se pueden conocer en exposiciones, tales como en las Bienales de Arte de la Fundación ONCE, en museos concretos como el Tiflológico en Madrid, donde se recopila la obra de más de una treintena de artistas ciegos o deficientes visuales, o el Museo Omero en Ancona, donde se exhibe la obra del escultor ciego Felice Tagliaferri, etc., consiguiendo de esta manera igualarse al resto de artistas sin discapacidad y logrando su inclusión social, sin olvidar que durante mucho tiempo estos artistas habían sido marginados del proceso creativo artístico, tanto en la apreciación del arte como en su elaboración.

Estas barreras de discriminación se superan a través de la educación, de instituciones relacionadas con el mundo del arte, universidades y organizaciones de personas con discapacidad o focalizadas en diferentes discapacidades. No tener vista no significa estar privado de sensibilidad estética (Kant 1970: 17) y poder entrenar y desarrollar el resto de los sentidos como el oído, el gusto, olfato, percepción de obstáculos y en especial el tacto, con miras al goce artístico. La inclusión a través del arte es un paso más en la conquista por la igualdad, consiguiendo modos de expresar sentimientos y sacar a la luz impresiones a través de la creación personal. La dimensión expresiva de lo artístico posee una importancia primordial en la socialización, inteligencia y juicio de las personas y genera crecimiento y desarrollo cognitivo a través de las múltiples formas de comunicación que poseemos los individuos.

En este apartado nos hemos propuesto mostrar dos perspectivas diferentes que generan experiencias inclusivas a través del arte. Por un lado, obras de arte realizadas por artistas ciegos y sus impresiones y, por otro, obras realizadas por escultores videntes y que son tocadas y apreciadas por las personas con discapacidad visual. En el primero de los casos podríamos establecer un paralelismo con los autores literarios, creadores de una obra en que se trasluce 
su pensamiento, y en el segundo de los casos estaríamos ante un posible paralelismo con el traductor literario que lee e interpreta lo que el autor del texto original —en este caso concreto, del texto visual original- ha plasmado en su obra, tanto desde el punto de vista formal como de contenido, añadiendo a ello lo que para el traductor ha supuesto la lectura palpada de la obra.

Comenzamos con dos escultores sordociegos, lo que hace que su aprendizaje sea más dificultoso y que su obra sea mucho más interesante:

José María Prieto Lago (1960) nace en Covas (Vivero-Lugo) con sordera profunda y perdiendo la vista gradualmente debido a una enfermedad degenerativa. Desde muy joven se sintió atraído por el modelado y a los quince años de edad empezó a frecuentar el taller de Juan Luis Otero, prestigioso escultor local. Una de las características esenciales es el hecho de que son esculturas hechas para tocar; por tanto, la contemplación de su obra no solo es visual, sino táctil y es en este terreno en el que la suavidad del bronce muy pulido, las curvas y contracurvas, las formas ausentes y presentes, se hacen visibles y palpables. El resultado de su creatividad y expresividad se traduce en un tacto agradable, originalidad en su manera de plasmar y su sello personal en las formas sinuosas. Cuando le preguntamos sobre su trayectoria artística nos dice: "Mi discapacidad no fue una barrera insalvable, la sensibilidad de mis manos y mi imaginación convirtieron en realidad mis sueños".

Gracias a las manos de su maestro, el aprendizaje se irá transformando en creación que le irá absorbiendo por completo. Sus esculturas, creadas en bronce a partir de vaciados en madera, las define como un ejercicio de libertad; le gusta comunicar emociones con sus obras; con ellas vence el aislamiento de su discapacidad.

A José María los guías intérpretes le explican el mundo a través del sistema dactilológico, para que pueda hacerse una idea del entorno y se comunique. De este modo nos transmite sus sensaciones:

En mi estudio siempre estoy en soledad, con mi trabajo y el silencio. A veces hablo con las esculturas. Sus movimientos se entienden bien con mi imaginación. Cuando salgo fuera de mi estudio me resulta difícil hablar con las personas, me faltan ideas, no sé qué decir. Mis esculturas tienen las palabras que necesito para comunicarme con vosotros y esto me tranquiliza. De vez en cuando pienso si estaré loco, pero soy feliz y sonrío (Prieto Lago 1997: 3). 
Andrés Clariana Brú de Salas (1973) nace en Barcelona. Padece retinitis pigmentaria (síndrome de Husser) y sordera profunda. Estudia escultura en la Escuela Massana de Barcelona (Centro Municipal de Arte y Diseño). Realiza trabajos de modelado, yeso, moldes, resinas de poliéster, talla de piedra, madera y bronce. Clariana plantea una obra escultórica de indagación básicamente táctil, en la que se manejan formas redondeadas, con recovecos, que incitan a ser exploradas, descubiertas de forma detenida, pausada, en absoluto inmediata. Realiza sus trabajos de modelado, en moldes de escayola, diversas resinas, talla en piedra y madera. Trabaja otros materiales como el alabastro, cemento, madera de sapeli, bronce, madera de bubinga, terracota esmaltada, piedra Folgueroles, arcilla esmaltada...

Pero no sólo experimenta con las formas, sino también con los diferentes materiales, razón por la cual elige unos soportes que difieren no tanto a la vista como al tacto, unos soportes como la terracota, el esmalte, el cemento, la madera, la piedra o el bronce, que ofrecen diferentes lecturas de la obra según su propia textura, su particular sensación térmica. Sorprende, pues, la forma, pero profundamente el tacto y lo que de él se desprende, la calidez o no del material, su grado de aspereza o lisura, su forma de absorber o emanar el calor recibido. De esta manera, Clariana hace al espectador partícipe de una serie de sensaciones que le permiten desarrollar un conocimiento de la obra puramente sensual, alejándole del tradicional conocimiento intelectual que le ofrece la exploración de la obra a través de la vista.

Su obra va expresando el progreso de las percepciones, así como los resultados de una tenaz y continuada investigación donde nos deja ver el ritmo de los perfiles, la alternancia de los volúmenes y el gusto por la sencillez, que nos conducen a un conjunto de sugestiones de carácter visual y táctil. Comenta el artista que durante el proceso artístico disfruta del placer de creación y ha asumido la escultura como el motor de su vida. Hasta tal punto es completa su dedicación que asegura que:

En ese momento, toda mi expresión y mis sentimientos guardados durante años en mi interior afloraron.... a veces hablo con las esculturas. Sólo puedo expresar mis conocimientos a través de ellas. Otras veces, las que hablan son las propias esculturas. (Clariana 1999:2).

Continuamos con el testimonio de otro creador deficiente visual como es Juan Torre, fotógrafo nacido en Getxo (Bizkaia) en 1956. Juan fue redactor 
gráfico hasta que se le declaró la enfermedad. A raíz de esa dolencia visual, sus obras experimentaron una transformación, no sólo en el modo de realizarlas sino también en el modo de concebir el resultado, buscando que el medio fotográfico fuera más accesible a personas con discapacidad:

El Síndrome de Behçet me aparece hace muchos años, cuando trabajaba en prensa en Diario 16. Después tuve un periodo de rechazo hacia la fotografía y finalmente volví otra vez a ella. En fin, el proceso ha sido largo porque me costó mucho aceptar y asimilar todo esto. A nivel fotográfico digamos que yo me siento más relajado a la hora de hacer fotos de un estilo determinado, no me siento diferente. Pero hay muchas cosas que no puedo hacer que antes sí hacía... En ese sentido una vez que aceptas tu limitación ves las cosas de una manera más natural, yo siempre me he sentido muy perfeccionista en la fotografía y en el trabajo. Pero ahora llego adonde llego y tampoco me vuelvo loco para dar exactamente con lo que quiero hacer. Realmente en mi cabeza creo que veo lo mismo, sigo viendo fotos cuando voy por la calle, y si voy a hacer algún trabajo concreto, pues en casa o donde sea, o en el estudio depende del tipo de trabajo que vaya a hacer. Me refiero a que mi manera de sentir la fotografía es exactamente la misma. Esta limitación me toca en lo que más me podía doler, mi vida había sido desde ese momento la imagen, pero ahora lo vivo de una manera más relajada y hay otras cosas a mi alrededor (Torre Mollinedo 2010: 3).

Actualmente, Juan Torre realiza fotografías en relieve, a las que se les añaden texturas que permiten, con bastante precisión, identificar al tacto los diferentes materiales que representan los diversos tejidos, la piel de las personas retratadas, y accesorios como gafas o relojes. El resultado final es una impresión fotográfica original, a la que se incorpora el relieve.

Entramos ahora en el segundo apartado, a modo de rescatar otro tipo de testimonios, tal y como habíamos mencionado más arriba: el de artistas famosos cuyas obras se pueden tocar y apreciar por personas con discapacidad visual.

En el año 2016 se realizó una exposición sobre la experiencia táctil titulada Descubrir a Miró con el tacto, durante la edición de la feria Art Madrid, en la que gracias a sus organizadores se hizo posible que personas con discapacidad visual pudieran acceder de manera normalizada, sin impedimentos ni limitaciones, al arte. En ese momento se recogieron opiniones e impresiones de las sensaciones y comentarios de los participantes, todos ellos ciegos, descubriendo las esculturas realizadas por Joan Miró. 
El primero de esos testimonios es de Asier Vázquez, periodista y poeta ciego interesado en el arte contemporáneo, que a su vez dirige el recorrido de la exposición:

Como aficionado al arte, haber podido tocar todas esas esculturas de Miró en el marco de Art Madrid ha sido todo un privilegio y una experiencia maravillosa. En este sentido, haber podido cumplir el deseo explícito de su autor de hacer accesible a todo el público su obra a través del permiso de su familia, engrandece al propio Miró y nos convierte en protagonistas de un hecho singular que resulta emocionante y muy hermoso. Además, haber podido ser a la vez guía de otras personas ciegas, como yo, que se han conmovido y han disfrutado del momento, ha completado el círculo.

Otro argumento se lo debemos a las palabras de Mariano Fresnillo, comunicador, periodista y escritor ciego.

Enfrentarme de nuevo al arte contemporáneo a través de las obras de Miró me seducía mucho. Por un lado, al ser un tipo de arte tan subjetivo que creo da igual lo veas o lo toques, pues la percepción consiste más en el concepto global de la obra que percibes. Por otro lado, tener la oportunidad de, como a él le gustaba, apreciar sus obras de arte con las manos.

El primer contacto me sorprendió con una obra que aglutinaba aspectos muy chocantes y difíciles de interpretar, la titulada Souvenir de la Tour Eiffel (1977). Me gustaba la sensibilidad del bronce y cómo simulaba el mimbre. Otros aspectos que luego fueron comunes y recurrentes en otras obras, como es la naturaleza.

Cuando concluía el recorrido táctil de cada obra, me preguntaba qué había querido transmitir con esa pieza y en muchas, era difícil saberlo. Luego te das cuenta que eso es lo de menos y me recreé más en los tipos de textura y qué me decía cada obra.

En algunas encontré silencio, pues no me transmitieron nada, pero sí hubo otras que me resultaron chocantes o me provocaron alguna reacción de sorpresa. Entre ellas por ejemplo la que compuso con un trozo de leño encontrado en el campo que además me dio la oportunidad de conocer la técnica de la cera perdida. También me gustó la del perrito Chien, por original. Creo que hay que acercarse a Miró y más con el tacto y eso sí, cuando lo hagáis, llevar a alguien que os guíe en el tocamiento de la obra pues como me pasó a mí, confundí unos brazos abiertos, muy largos de una mujer, con sus piernas y claro que, si no me corrigen, el significado de esa $u$ otra obra puede cambiar radicalmente, con la obra titulada Gymnaste (1977). Gracias a todos los que hicieron posible que viviera esta experiencia táctil una vez más. 
Diferente es el testimonio de Miguel Moreno (1952), ciego desde los seis años, licenciado en Psicología por la Universidad Autónoma de Madrid, que realizó la labor de coordinador del Museo Tiflológico durante los últimos años de su vida laboral:

Me gustó bastante la buena explicación que disteis de las esculturas, sabiendo que no es fácil explicar a Miró. Me gustó diferenciar las texturas de las diferentes esculturas del recorrido. Me gustó mucho volver a tocar Souvenir de la Tour Eiffel, obra que toqué hace bastantes años, pero para mí fue una emoción importante volver a descubrirla. Se me hizo corta la visita y propondría hacer grupos diferenciados entre los que tocan más despacio, y los que ya tenemos cierta experiencia, por lo tanto, la exploración táctil es más rápida.

Por último, tomamos el testimonio de un escultor que se vanagloria de hacer esculturas para ser tocadas: se trata de Alfonso Salas. Una de sus exposiciones la realizó en la sala de exposiciones temporales del Museo Tiflológico, en el año 2003, donde un gran número de personas ciegas y deficientes visuales pudieron contemplar y tocar su obra, para deleite de todos.

En un catálogo titulado Salas, dedicado por completo a este artista y según aprecia y relata Mario Ángel Marrodán, el escultor lleva por lema la fuerza de la persuasión desde el pleno conocimiento de las cualidades físicas de la materia. Habla de las texturas, en compenetración total con la materia. Para enfatizar la expresividad retoca el brillo, el tacto, el patinado, las proporciones para redondearla, dotándola de espíritu al recrearse con los detalles. Modela la piedra con formas sugerentes, a través de concavidades y convexidades, quedando la escultura envuelta en un aura especial, queriendo reflejar los sentimientos en cada talla, proporcionándole vida, en el lenguaje de la humanidad.

Sus formas escultóricas conversan con el espectador. Se las puede disfrutar cuando se ven y comprender cuando se palpan. La concepción escultórica de Alfonso Salas está habitualmente basada en el ritmo y en el equilibrio de la figura. Porque su escultura es física y psíquica, táctil y anímica: cuerpo y alma, y porque contiene sentimiento de quietud y carácter litúrgico, Alfonso Salas queda debidamente representado en ella como religioso, como persona, como creador, como hombre y como artista que trabaja con las manos, pero esculpe con el alma (Marrodán 2003: 27). 
Para finalizar, tal y como se recoge en el epílogo del mismo catálogo, redactado por Alberto Iglesias Sanz, se afirma sobre Alfonso Salas, escultor-teólogo de la Orden de Predicadores:

La conjugación de lo humano y lo divino, de lo corriente y lo sublime, de lo exterior e interior, de la materia y el alma, surge de una manera espontánea y natural en la obra de Salas, como el ladrido y el respiro. (Marrodán 2003: 41)

En las obras de Alfonso Salas encontramos un misticismo teológico junto a la suavidad y perfección que reúne el escultor, creador de obras que pueden ser vistas y apreciadas por todas las personas.

\section{Reflexiones finales a manera de conclusiones}

El propósito de este artículo es destacar que el conocimiento y aprehensión de conceptos abstractos en el campo histórico-artístico no solamente puede darse a través de textos, sino que también se puede contemplar la interpretación de conceptos de modo táctil, como hemos podido comprobar a lo largo de las dilucidaciones históricas, de las teorías sobre la traducción y trasmisión de conocimientos a los deficientes visuales tanto a través de la verbalización, como con el propio testimonio tanto de artistas ciegos, sordociegos y escultores que no olvidan el tacto ni el sentido háptico de la escultura. El término háptico procede del griego háptō, y define la ciencia que trata el tacto como el estudio del comportamiento del contacto y percepción que utiliza de forma volitiva la información obtenida mediante la exploración táctil y el movimiento en el que están implicados la piel, los músculos y las articulaciones, para obtener la información (Consuegra 2000: 151), lo que está muy relacionado con la escultura porque se puede abarcar con una, con dos manos, o con el cuerpo y poder abrazar.

Uno de los medios de ofrecer información es la transmisión oral que se produce mediante una descripción a través del sistema auditivo, lo cual posibilita el aprendizaje sobre realidades que no pueden alcanzarse con la vista, y se complementa con el tacto, con el que poco a poco y a base de la percepción mediante el sentido del tacto se consigue la agudeza táctil de la información del objeto, influida por el tamaño, la riqueza de texturas, contrastes de colores a través de estas texturas, complejidad de las formas, etc., y procesar la información que llega del tacto a la mente. 
Habitualmente la descripción se realiza sobre imágenes u objetos bidimensionales en relieve, realizando una traducción de esas imágenes en palabras con la dificultad que ofrece el hecho de que las imágenes son multidimensionales y el lenguaje es lineal. Debido a este hecho siempre surge la duda de si la traducción cumple su objetivo, particularmente en el campo de las obras de arte, dado que la descripción puede resultar fiel a la función del objeto, pero puede generar dudas a la hora de transmitir su apariencia.

En la investigación en traducción es común hablar del traductor como mediador lingüístico y cultural. En el caso de los mediadores culturales que explican las obras a personas con discapacidad visual, no cabe duda de que esta figura de mediador cultural en los museos ejerce las funciones de intérprete de las obras y de su valor histórico-artístico teniendo en cuenta al destinatario y el valor del sentido háptico.

A modo de conclusión diremos que una buena traducción de conceptos, en el sentido de una transmisión adecuada de los mismos, adaptada al público receptor con discapacidad visual, unida a una buena interpretación oral, hará viable la comprensión de contenidos que permitan el acceso a las manifestaciones del arte plástico y disfrutar de los valores estéticos, intelectuales, socioculturales y emocionales, con garantías de éxito.

\section{Referencias Bibliográficas}

ARISTÓteles. (1970) Política, capítulo XVI, versículo 1335. Edición bilingüe y traducción por Julián Marías y María Araujo. Instituto de Estudios Políticos, Madrid.

BONET, Juan Pablo. (1620) Reducción de las letras y Arte para enseñar a hablar a los Mudos. Madrid.

Clariana Bru de Sala, Andrés. (1999) "Catálogo de la exposición." Museo Tiflológico.

CONSUEGRA CANO, Begoña. (2000) "Comunicación y visitantes con discapacidad visual en espacios expositivos." Boletín ANABAD 50:1, pp. 143-158.

Hurtado Albir, Amparo. (2001) Traducción y Traductología. Introducción a la Traductología. Madrid: Cátedra.

KANT, Immanuel. (1970) "Summa Pictórica, de las Vanguardias a la Postmodernidad." Tomo X. Editorial Planeta, pp. 17-24. 
LUZ ARQUÉ, Mercè. (2005) "Arte-Ceguera." Integración (Revista sobre ceguera y deficiencia visual) 45, pp. 17-24.

MArrodán, Miguel Ángel. (2003) "Estudio de la escultura reciente de Alfonso Salas." En catálogo titulado "Salas" Alfonso Salas Esculturas.

Martino AlBA, Pilar. (2016) La autobiografía artística como problema de traducción. Alicante: Universidad de Alicante. Versión electrónica: https://rua.ua.es/ dspace/bitstream/10045/54768/1/tesis_pilar_martino_alba.pdf

Palacios Rizzo, Agustina. (2008) El modelo social de discapacidad: orígenes, caracterización y plasmación en la Convención Internacional sobre los Derechos de las personas con Discapacidad, Madrid: CERMI.

Prieto Lago, José María. (1997) "Catálogo de la exposición." Museo Tiflológico. SÁEz Hermosilla, Teodoro. (2002) El sentido de la traducción. Reflexión y crítica. León: Universidad de León, Secretariado de Publicaciones y Medios Audiovisuales.

TORRE Mollinedo, Juan. (2000) "Catálogo de la exposición.” Museo Tiflológico. Vega Cernuda, Miguel Ángel. (2013) "Momentos estelares de la traducción en Hispanoamérica." Mutatis Mutandis 6:1, pp. 22-24.

VIVES, Juan Luis. (1526) De subventione pauperum. Sive de humanis necessitatibus libri II. Brujas, Bélgica.

\section{BIONOTA / BIONOTE}

TERESA DíAz DíAZ es Licenciada en Historia del Arte por la Universidad Complutense y especializada en Arte Español y Arte Medieval. Es autora de 11 artículos publicados en medios especializados y relacionados con el arte en general como son la revista Pasos de Arte y Cultura, Cuadernos de Etnología de Guadalajara, entre otros, concernientes a escultura, arquitectura, pintura, etnografía, etc., además de participar con 16 colaboraciones en obras colectivas como son el Simposium del Instituto de Investigaciones Históricas y Artísticas de El Escorial, Encuentros de Historiadores del Valle del Henares, entre otros. De 1998 a 1990 ejerció como profesora de alfabetización para adultos en la Escuela Popular de Prosperidad (Madrid). Trabajadora en la ONCE desde hace treinta y cuatro años, de los cuales veintidós se encuentra realizando la labor pedagógica y los trabajos como técnico de comisariado en cuanto a montaje y desmontaje de exposiciones del Museo Tiflológico. 
TERESA DíAz DíAz holds a degree in Art History from the Complutense University and specialises in Spanish Art and Medieval Art. She is the author of 11 articles published in specialised media related to art in general, such as the magazine Pasos de Arte y Cultura, Cuadernos de Etnología de Guadalajara, among others, concerning sculpture, architecture, painting, ethnography, etc.., in addition to participating with 16 collaborations in collective works such as the Symposium of the Institute of Historical and Artistic Research of El Escorial, Encuentros de Historiadores del Valle del Henares, among others. From 1998 to 1990 she worked as a literacy teacher for adults at the Escuela Popular de Prosperidad (Madrid). She has been working at ONCE for thirty-four years, of which she has spent twenty-two carrying out the pedagogical work and the work as curatorial technician for the assembly and dismantling of exhibitions at the Museo Tiflológico. 